\title{
Detection of syphilis and other pathogens associated with genital lesions using PlexPCR ${ }^{\mathrm{TM}}$
}

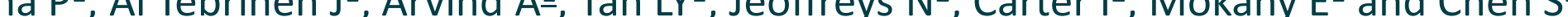

'SpeeDx Pty Ltd, National Innovation Centre, Sydney, Australia, ${ }^{2}$ Victorian Infectious Diseases Reference Laboratory, Melbourne, Australia

\section{Background}

$>$ Syphilis, caused by Treponema pallidum subsp. pallidum (T. pal), is responsible for lesions at a variety of body sites

$>$ Herpes simplex virus 1 (HSV-1) \& herpes simplex virus 2 (HSV-2) cause lesions at a variety of cutaneous and mucocutaneous sites

$>$ Primary infection with Varicella zoster virus (VZV) causes chickenpox, and reactivation later in life produces shingles

$>$ Skin \& genital lesions have similar clinical presentation for all four organisms ${ }^{1,2}$

- In Australia, population estimates are $85 \%$ carrying HSV-

1 and $20 \%$ carrying HSV-2 ${ }^{3}$

- Up to $3 \%$ of genital swab samples are VZV4

VZV requires different treatment/therapeutic intervention to HSV-1 \& HSV-2 4

- After hitting lows in 2001 , the rate of syphilis infections is increasing ${ }^{2}$

Identification of organism crucial for correct clinical management

\section{PlexPCR ${ }^{\text {TM }}$ technology for NAATs}

PlexZyme ${ }^{\mathrm{TM}}$ detection in qPCR is highly specific \& sensitive

$>$ Superior performance in multiplex

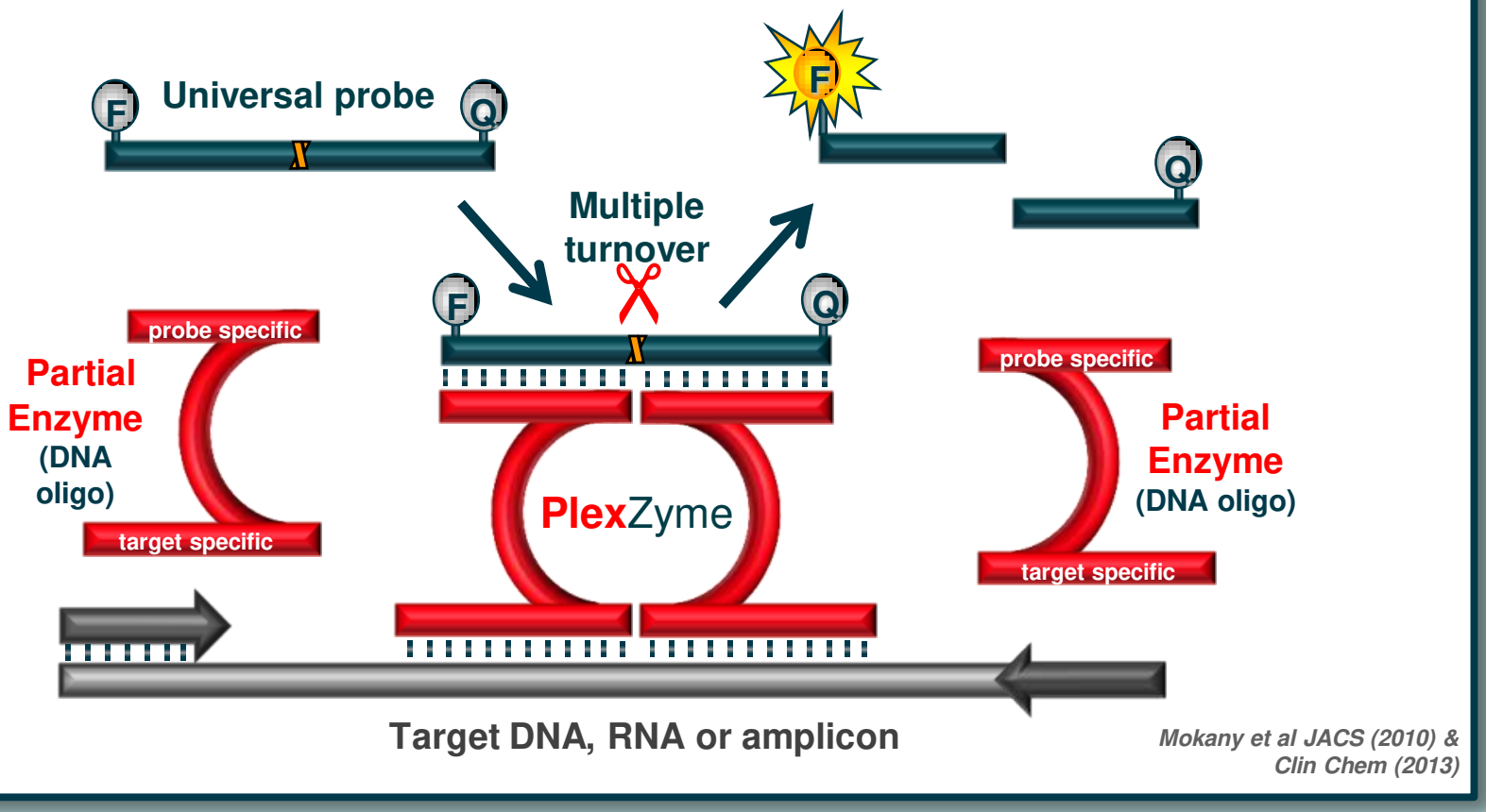

\section{Analytical specificity}

\begin{tabular}{|c|c|c|c|}
\hline Organism & Conc & Organism & Conc \\
\hline Neiseseria gonorrhoeae & \multirow{9}{*}{$\begin{array}{c}10^{4} \text { copies } \\
\text { per assay }\end{array}$} & Haemophilus influenzae & \multirow{9}{*}{$\begin{array}{c}10^{6} \text { copies } \\
\text { per assay }\end{array}$} \\
\hline Mycoplasma hominis & & Neisseria meningitidis & \\
\hline Trichomonas vaginalis & & Enterococcus faecalis & \\
\hline Mycoplasma pneumoniae & & Escherichia coli & \\
\hline Ureaplasma parvum & & Klebsiella pneumoniae & \\
\hline Ureaplasma urealyticum & & Pseudomonas aeruginosa & \\
\hline Chlamydophila pneumoniae & & Streptococcus pneumoniae & \\
\hline Human herpes virus 6 & & Haemophilus ducreyi & \\
\hline Epstein Barr virus & & Chlamydia trachomatis & \\
\hline
\end{tabular}

No cross-reactivity with a wide range of organisms

\section{Clinical Evaluation}

\section{PlexPCR $^{\text {TM }}$ vs Westmead In-house Assay}

$>$ The performance of the assay was evaluated using clinical samples obtained from Pathology West, Sydney, in a retrospective study comparing the SpeeDx and in-house assays.

HSV-1 detection

\section{$\times$} 变 के Total Specificity $97.1 \%(95 \% \mathrm{Cl} 90.0-99.2 \%)$

\begin{tabular}{|c|c|c|c|c|}
\hline \multirow{2}{*}{\multicolumn{2}{|c|}{$\begin{array}{c}\text { VZV } \\
\text { detection }\end{array}$}} & \multicolumn{3}{|c|}{ In-house qPCR } \\
\hline & & + & - & Total \\
\hline \multirow{3}{*}{$\begin{array}{l}\text { ô. } \\
\text { \% } \\
\text { के }\end{array}$} & + & 40 & 1 & 41 \\
\hline & - & 1 & 33 & 34 \\
\hline & Total & 41 & 34 & 75 \\
\hline
\end{tabular}

HSV-2 In-house qPCR detection + + - $\quad$ Total \begin{tabular}{|c|c|c|c|c|}
\hline $\mathbf{x}$ & + & 23 & 0 & 23 \\
\hline $\mathbf{Q}$ & - & 0 & 81 & 81
\end{tabular} के Total $23 \quad 81 \quad 104$ Sensitivity $100.0 \%(95 \% \mathrm{Cl} 85.7-100 \%)$ Specificity $100.0 \%$ (95\% Cl $95.5-100 \%)$

\begin{tabular}{|c|c|c|c|c|}
\hline \multirow{2}{*}{\multicolumn{2}{|c|}{$\begin{array}{c}\text { T. Pal } \\
\text { detection }\end{array}$}} & \multicolumn{3}{|c|}{ In-house qPCR } \\
\hline & & + & - & Total \\
\hline \multirow{3}{*}{ 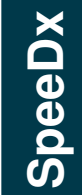 } & + & 87 & 0 & 87 \\
\hline & - & 5 & 11 & 16 \\
\hline & Total & 92 & 11 & 103 \\
\hline
\end{tabular}

High sensitivity and specificity with clinical samples

\section{Analytical sensitivity}

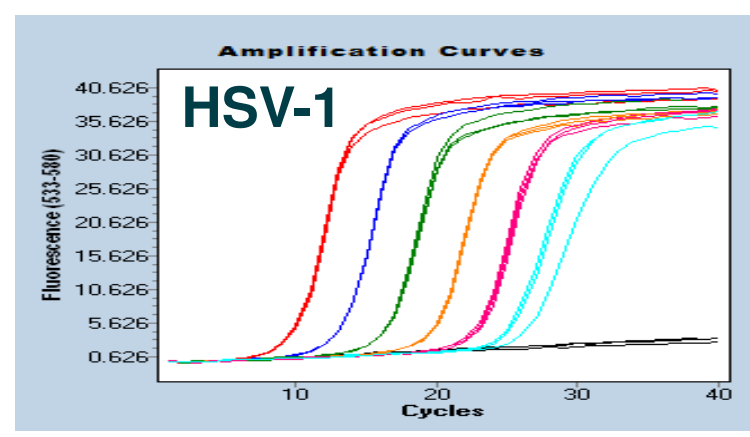

$E=103.5 \% \quad R^{2}=0.999$

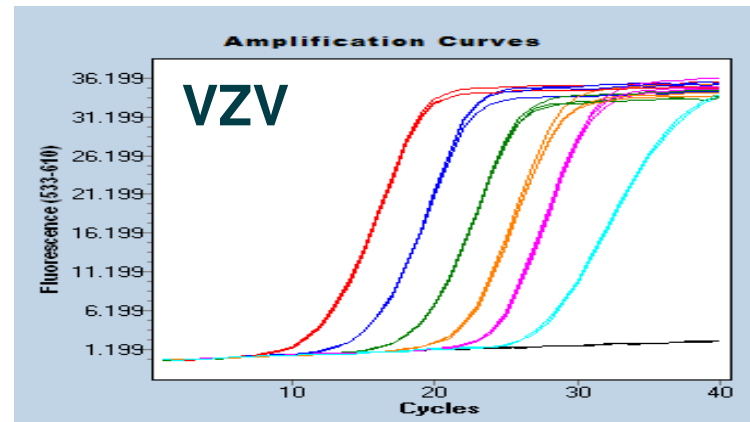

$E=113.6 \% \quad R^{2}=0.996$

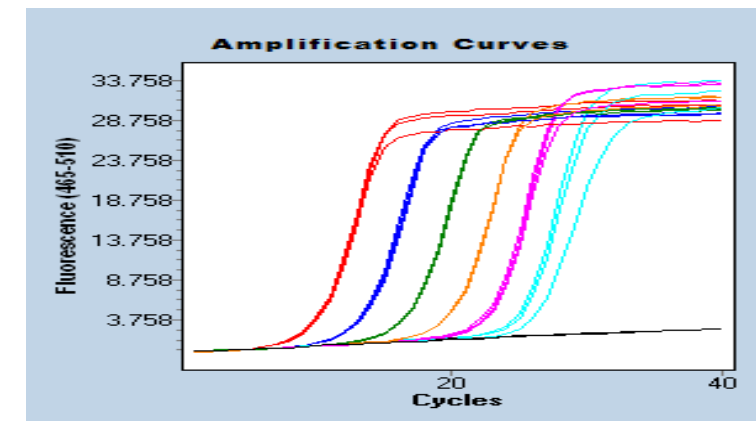

$E=109.9 \% \quad R^{2}=0.997$

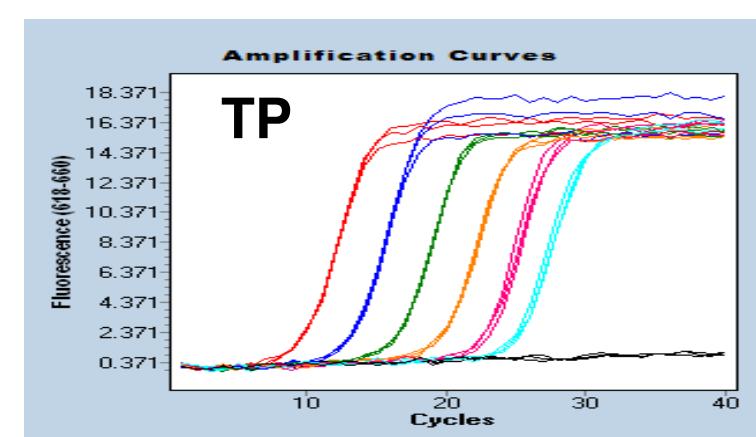

$E=108.7 \% \quad R^{2}=0.996$
Detection to 10 copies per assay

\section{Conclusions}

> The PlexPCR ${ }^{\mathrm{TM}}$ HSV-1\&2, VZV, Syphilis test (SpeeDx) provides sensitive, specific and rapid detection of pathogens causing cutaneous and mucocutaneous lesions.

There was excellent concordance between the SpeeDx and Inhouse assays on a range of clinical samples.

References: 1. Simon HK, Steele DW. Ann Emerg Med. (1995); 2. CDC Syphilis fac sheet. https://www.cdc.gov/std/syphilis/stdfact-syphilis-detailed.htm. 3 .

http://www.sexualhealthaustralia.com.au/genital herpes.html ; 4. Birch CJ et al. Sex Transm Infect (2003) 